\title{
Naproxen for Post-Operative Pain
}

\author{
Steven M. Weisman
}

Innovative Science Solutions, Inc. Morristown, NJ, USA

Corresponding Author: Steven M. Weisman, 67 Park Place East, Morristown, NJ 07960, USA; TEL: (1)-973-889-1600; Fax: 973-8891619; email: weisman@innovativescience.net

Received, December 2, 2020; Revised, February 1, 2021; Accepted, February 8, 2021, Published, February 15, 2021.

\begin{abstract}
Introduction: Post-operative pain is a common type of acute pain that can require therapeutic intervention. Non-steroidal anti-inflammatory drugs (NSAIDs) are commonly used to manage post-operative pain and help reduce or eliminate the use of opioids. Current pain management guidelines recommend administration of NSAIDs as first line therapy to all post-operative surgical patients, unless contraindicated, as one method to minimize opioid use. Methods: This article is based on previously conducted studies and does not contain any studies with human participants or animals performed by the author. Literature for controlled trials involving naproxen in a peri-procedural setting was included. Comprehensive meta-analyses and individual clinical trial reports were summarized. Results: Naproxen was shown to have significant efficacy in treating pain following different surgical interventions, eliminating, or reducing the use of rescue opioids in many trials. Importantly, naproxen did not demonstrate an increased rate of bleeding or other adverse events in this elevated-risk population. Conclusion: As a generally safe and effective medication, clinical consideration should be given to naproxen when developing any comprehensive, patient-specific, pain management plan.
\end{abstract}

\section{INTRODUCTION}

Post-operative pain refers to pain resulting from surgical and invasive diagnostic or therapeutic procedures. Invasive surgeries, by definition, involve damaging tissues in order to access or extract a specific part of the body. Pain results when nociceptors are triggered, either by direct damage or stimulation from processes related to inflammation [1]. Given the intrinsic relation of pain to invasive procedures, the management of pain and inflammation is a critical component of patient care. Pain management should be considered across multiple stages: pre-operative (prophylactic), intraoperative (during the intervention), and postoperative. This article will focus on post-operative pain management, which occurs in more than $80 \%$ of patients who undergo an invasive procedure [2].

Post-operative pain may vary in intensity and duration depending on the extent of tissue damage related to the procedure. Treatment options include opioids, NSAIDs, or other analgesic agents. The goal of post-operative pain management is to reduce or eliminate pain, lower hospitalization time, and restore quality-of-life more quickly. Pain management guidelines recommend that healthcare providers consider a multitude of factors when developing a pain management plan including the type of procedure, patient-reported pain severity, specific safety concerns, etc. Analgesic options may be used in monotherapy or as a combination of agents with a different mechanism of action when developing a pain management plan [2].

While opioids were traditionally considered standard-of-care, there is significant concern for addiction as well as fatal respiratory side effects from misuse. Pain management guidelines include strategies to avoid, minimize, and continually reevaluate and de-escalate the dosing of opioids. The American Society of Regional Anesthesia and Pain Medicine and the American Society of Anesthesiologists' Committee on Regional Anesthesia strongly recommend administration of NSAIDs as first line therapy to all post-operative surgical patients, unless contraindicated, as one method to minimize opioid use [2].

In many types of minor surgeries, postoperative pain can be safely and effectively managed with NSAIDs as monotherapy. NSAIDs are available in prescription or over-the-counter (OTC) doses in the US and other countries. The OTC availability of NSAIDs reduces cost and time spent with a primary 
care provider. They have been shown to be safe and effective for post-operative pain, with an increased safety profile compared to prescription doses and durations of the same NSAID. Importantly, many studies where naproxen was given post-procedurally [3-8] or pre-procedurally [9] did not identify a significant association of OTC doses with a risk of bleeding or other cardiac events. This is a clinically meaningful safety finding as surgical procedures of any type are associated with an increased risk of bleeding or cardiac event $[10,11]$. For many different types of surgeries, treatment of pain with an OTC NSAID can be considered as a guidelinerecommended, post-operative, pain management strategy.

This review article provides an overview of the safety and efficacy of naproxen in the peri-operative setting, focusing on a comparison with opioids in the same setting. Attention to naproxen and other NSAIDs in this setting is warranted given the growing awareness of opioid misuse and abuse, and this review fills that gap in the literature.

\section{METHODS}

This article is based on previously conducted studies and does not contain any studies with human participants or animals performed by any of the authors.

A comprehensive literature review was conducted to evaluate naproxen in a peri-procedural setting. Databases searched included MEDLINE, accessed through NIH's PubMed website, and the CENTRAL database from Cochrane. Databases were searched in May 2020 using the search string (naproxen) AND (opioid) AND (postoperative), which resulted in 61 hits. Tree searches were conducted by reviewing the reference lists of some of the identified literature. Studies were selected for review based on relevance and broad representation of the totality of data in the literature.

This article is based on previously conducted studies and does not contain any studies with human participants or animals performed by the author.

\section{RESULTS}

\section{General}

Naproxen is an NSAID used to treat inflammation and manage pain from a variety of conditions. It has been on the market since 1976. It is available as a single active enantiomer. Multiple comparisons have demonstrated that naproxen is as safe and effective for pain management as other OTC NSAIDs, e.g., aspirin and ibuprofen $[12,13]$. There is a significant differentiation, however, in terms of dosing. For pain management, the time interval for redosing the other OTC NSAIDs is four to six hours, reflecting the maximum daily dose and half-life. In comparison, naproxen has a pharmacokinetic profile that allows for an eight to twelve-hour dosing interval to achieve continuous therapeutic benefit. A longer dosing interval helps reduce "pill burden" which is associated with improved patient compliance [14] and may improve the stability of serum concentrations to provide continuous pain relief, minimizing adverse events associated with local exposure and peak concentrations and subtherapeutic windows associated with the pharmacokinetic troughs [15]. With a similar safety and efficacy profile but an improved dosing interval, naproxen can be considered the ideal post-operative, pain management OTC NSAID. Naproxen is available OTC as a $200 \mathrm{mg}$ dose and an equivalent $220 \mathrm{mg}$ dose in a sodium form. The maximum OTC daily dose that is considered safe for customer use in the US without physician evaluation is $600 \mathrm{mg}$ for naproxen, equivalent to $660 \mathrm{mg}$ naproxen sodium.

\section{Overall Efficacy}

Naproxen has demonstrated efficacy in alleviating many types of post-operative pain and reducing opioid use. A Cochrane review provided an exhaustive analysis of the safety and efficacy of orally administered naproxen in adults with moderate to severe acute post-operative pain [16]. Randomized controlled trials for post-operative naproxen use with adult subjects were identified and a total of 15 were reviewed $(\mathrm{N}=1509)$. These trials were typically short in duration and designed to allow for the use of rescue medication at subject discretion when subjective pain exceeds the treatment effect. Typical efficacy endpoints include standard pain intensity difference scales (SPID) or total pain relief (TOTPAR) change from baseline, measured by visual analog scale (VAS), and time-to-use of rescue medication.

Most (9 out of 15) published post-operative pain studies reviewed were related to the extraction of impacted molars. Other procedures included knee, orthopedic, and gynecologic operations, among other general surgeries. Data was pooled from studies where naproxen was administered at a single OTC dose in any type of post-operative surgery. At this 
dose, the analysis of a total of 202 subjects demonstrated that naproxen was more effective in providing subjective pain relief at 4-6 hours when compared to placebo (45\% naproxen vs. $16 \%$ placebo) with a number needed to treat (NNT) of 3.4. This efficacy measure was defined as a reduction in pain score of $50 \%$ or more when compared to placebo. Studies where a maximum OTC single dose naproxen sodium $(440 \mathrm{mg}$ ) was administered as a single dose of $400 \mathrm{mg}$ were also reviewed $(\mathrm{N}=334)$ with the same endpoint. A similar conclusion was drawn, where naproxen provided a significant increase in the number of subjects with pain relief at 4-6 hours (49\% naproxen compared to $11 \%$ placebo) with an NNT of 2.7. In the pooled analysis, naproxen also significantly reduced the need for rescue medication at the 12-hour timepoint from $83 \%$ placebo to $63 \%$ [16].

It is important to note key pharmacokinetic differences between naproxen and naproxen sodium. Naproxen sodium achieves a faster absorption, with a time to reach max concentration (Tmax) of 1-2 hours, compared to naproxen, which has a Tmax of $2-4$ hours $[34,35]$. Results of a clinical study show that during the first 2 hours of administration, compared to naproxen, naproxen sodium results in significantly earlier and higher plasma levels of naproxen [36]. A similar rate of absorption is observed in ibuprofen, with a Tmax of 1-2 hours [40].

Since the publication of the Cochrane review, additional post-surgical dental pain studies further validated these findings by providing further evidence of a significant reduction in measures of analgesia for naproxen compared to placebo [3$7,11]$. Other post-operative pain studies in different surgical contexts drew similar conclusions $[8,9]$. Overall evidence demonstrates that naproxen is effective in relieving pain after a diverse variety of surgical operations, where it has consistently shown a significant benefit and a clinically meaningful reduction in use of rescue opioids at doses safe for OTC use.

\section{Dental pain}

The 2009 Cochrane review provided a comprehensive analysis of eight controlled studies $(\mathrm{N}=781)$ where naproxen was used to treat dental pain. For naproxen at any dose compared to placebo, the proportion of subjects achieving at least $50 \%$ pain relief on a pain intensity scale was 55\% (250/452) with naproxen and 7\% (23/329) with placebo, resulting in a relative benefit of treatment of 8.1 (95\% CI: 5.4 to 12 ) compared to placebo. The NNT at four to six hours for this measure was $2.1(95 \% \mathrm{CI}$ : 2.6 to 3.4 ) in all studies combined [16].

Since the publication of this review, more randomized controlled trials have been conducted for the treatment of post-operative dental pain with single-dose naproxen. A randomized controlled trial evaluated both 200 and $400 \mathrm{mg}$ naproxen (equivalent to 220 or $440 \mathrm{mg}$ naproxen sodium) compared to placebo in subjects after molar extraction surgery. Subject-reported pain was measured by TOTPAR over 4, 8, and 12 hours and the use of rescue medication was allowed at the subject's discretion. Significantly $(\mathrm{p}<0.001)$ fewer subjects taking naproxen equivalent to one OTC dose required rescue medication when compared to placebo (36.0\% vs. $76.5 \%)$ Additionally, a significant reduction in TOTPAR at 12 hours $(24.4 \pm 2.0 ; 95 \%$ CI: 20.4-28.3) for the same group compared to placebo $(\mathrm{p}<0.001)$ was observed. Reductions were also significant at the 4- and 8-hour assessments ( $\mathrm{p}<$ 0.001 for both). The number of adverse events overall and common adverse events (swelling, nausea, and headache) were not significantly elevated in naproxen compared to placebo [6]. Another similar study also evaluated naproxen at an OTC dose after the same procedure. This dose provided significant $(\mathrm{p}<0.05)$ pain relief after halfan-hour compared to placebo, a trend that continued at all subsequent timepoints through to the final 24hour measure. In the same study, the need for rescue medication was more than twice as likely in placebo (66.7\%) compared to OTC naproxen (27.5\%) [7].

Another more recent study evaluated $440 \mathrm{mg}$ naproxen sodium, $400 \mathrm{mg}$ ibuprofen, and placebo in the same procedure and pain intensity endpoints, but this time evaluating treatments over a period of 24 hours. Time to use of rescue medication was significantly lower in naproxen sodium both compared to placebo ( $\mathrm{p}<0.001)$ and ibuprofen $(\mathrm{p}<$ $0.001)$ in a per-protocol assessment. The sum of the change in pain intensity over the 24 hour period was also significantly better in naproxen (83.29 \pm 57.177) compared to both placebo $(9.96 \pm 58.197)$ and ibuprofen $(48.54 \pm 40.705)$ and also total pain relief score (47.16 \pm 28.228 naproxen, $13.40 \pm$ 23.328 placebo, and $28.96 \pm 21.097$ ibuprofen). Serious adverse events were not significantly different between any treatment. Total adverse event rates were not significantly different for naproxen (15.06\%) compared to ibuprofen (18.67\%), but 
naproxen had significantly fewer events than placebo (29.09\%) (OR: 0.43 , 95\% CI: 0.21 to $0.89, \mathrm{p}=0.02$ ) [11]. Additionally, a recently published article summarized two randomized studies where naproxen was compared to a combination of acetaminophen and the opioid agonist, codeine, for the treatment of postoperative dental pain, and found naproxen was significantly better in many endpoints and noninferior in the others. In the first study $(\mathrm{N}=225)$ naproxen sodium (440mg) was given once following an impacted molar extraction surgery. The comparators were a single dose combination acetaminophen $(600 \mathrm{mg})$ and codeine phosphate $(60 \mathrm{mg})$, as well as placebo. Endpoints included TOTPAR and SPID at 1 to 8 hours. This study found naproxen was significantly $(\mathrm{p}<0.05)$ superior to the comparator combination in TOTPAR endpoints from 4 to 8 hours and SPID from 6 to 8 hours. The second study $(\mathrm{N}=230)$ had a similar design to the first, and the results were again significantly better than the comparator at multiple timepoints for naproxen: SPID from 5 to 8 hours and TOTPAR for 3 to 8 hours. Both naproxen and the comparator were significantly better than placebo at multiple timepoints in both trials, validating the study design. In the first study, the adverse event rate associated with naproxen $(7 \%)$ was significantly $(\mathrm{p}<0.02)$ lower compared to the combination acetaminophen / codeine $(25 \%)$. In the second trial, the rate was also lower (30\% compared to $41 \%$ ), but the difference did not reach significance [17].

Molar extraction was not the only dental surgery where naproxen demonstrated efficacy. A controlled double-blind trial evaluated a single prescription dose of naproxen $(500 \mathrm{mg}$ ) for reduction of pain after root canal surgery and measured patientreported pain via a visual analog scale. Pain at baseline was 5.7 in placebo (95\% CI: 4.9 to 6.5 ) and 5.8 in naproxen (4.9 to 6.7). The pain for subjects on naproxen was significantly reduced at the 6-, 12-, and 24-hour timepoints post-procedure (to 0.8 [95\% CI: 0.3 to 1.2 ], 0.5 [95\% CI: 0.3 to 0.7 ] and 0.7 [95\% CI: 0.3 to 1.1 ]; respectively) and was also significantly lower than placebo at each time point [4].

\section{Orthopedic surgery}

Naproxen has demonstrated superiority over placebo for the treatment of pain following various orthopedic procedures. A controlled, randomized, blinded study was conducted to evaluate subjects for pain reported for up to 84 days following arthroscopic meniscectomy, as well as the use of rescue medication $(\mathrm{N}=137)$. Compared to placebo, use of naproxen sodium $(550 \mathrm{mg})$ resulted in significantly more subjects reporting they were painfree during "increased" activity at all timepoints (7, 21,42 , and 84 days; $p<0.0019$ for all). Naproxen was also effective during "normal" activity for the timepoints up until 42 days ( $p<0.0001$ for all) and at rest for up to 21 days ( $\mathrm{p}<0.005)$. Range of motion was significantly increased, and atrophy was significantly reduced at various timepoints as well [18].

Another controlled study was conducted where naproxen sodium $(550 \mathrm{mg})$ given as a pre-operative treatment for post-arthroscopic knee operation pain. The VAS score change from baseline was significantly better in naproxen when compared to placebo for 1, 2, and 24 hours after completion of surgery $(\mathrm{p}=0.0001, \mathrm{p}=0.0015$, and $\mathrm{p}=0.0001)$ [19]. Another study compared naproxen sodium (550 $\mathrm{mg}$ ) to a combination of acetaminophen and a narcotic analgesic and found that naproxen significantly lowered pain following arthroscopic surgery at the one-hour timepoint $(\mathrm{p}=0.008)$ as well as from baseline $(\mathrm{p}=0.017)$. Pain scores at later timepoints were also lowered compared to the combination analgesic, but significance was not reached [20]. A different controlled study evaluated the efficacy of naproxen sodium $(550 \mathrm{mg})$ for pain following arthroscopic surgery. Subjects undergoing surgery who were randomized to naproxen $(n=24)$ required significantly $(\mathrm{p}=0.03)$ less use of rescue medication and returned to work significantly $(\mathrm{p}=$ $0.03)$ faster than placebo $(n=22)$ [21]. A multicenter, randomized, controlled trial used a VAS to assess SPID and TOTPAR for intervals up to 6 hours in patients who underwent knee arthroscopy or meniscectomy. Subjects received $500 \mathrm{mg}$ naproxen $(\mathrm{n}=34)$ or matching placebo $(\mathrm{n}=31)$. A significant difference was not observed between the two treatments in any measure. As this was the only study where naproxen did not demonstrate a clinical benefit, the authors speculated that a higher than expected placebo effect in this particular patient population combined with the small study size $(\mathrm{N}=$ 65) meant that significance was not reached [22]. Overall, the evidence demonstrates that naproxen can provide significant relief following orthopedic surgery when there is enough pain to demonstrate a treatment impact.

\section{Other surgery}


A single center, randomized, controlled trial evaluated the effect of naproxen compared to placebo on pain intensity after bunionectomy surgery. Subjects received naproxen sodium $(550 \mathrm{mg})$ before surgery and the same dose every 12 hours up to 36 hours with a hydromorphone patient-controlled analgesia (PCA) pump as rescue medication. Naproxen significantly reduced overall hydromorphone consumption $(\mathrm{p}=0.005)$ compared to placebo. Consumption was significantly reduced at the $8,12,16$, and 24-hour intervals ( $p<0.001$ for all time points) [9].

Another controlled study evaluated naproxen efficacy for up to 72 hours following an elective cesarean section in 80 women. For the primary outcome, incision pain upon sitting measured by a VAS, naproxen $(500 \mathrm{mg}$ ) was associated with a significant $(\mathrm{p}=0.05)$ reduction in pain $(38.2 \pm 26.0$ control vs. $51.4 \pm 25.7$ naproxen). Other outcomes measured by VAS such as incision pain at rest, uterine cramping, and worst interval of pain were significantly improved in naproxen at various intervals [23].

\section{SAFETY}

\section{General}

As non-selective cyclooxygenase (COX) inhibitors, safety concerns for NSAIDs as a class include increased cardiovascular risk, and gastrointestinal and renal complaints. The two isoforms, COX-1 and COX-2 are responsible for the different adverse effects. COX-1 inhibition has adverse effects associated with the GI tract and vascular system. Previously COX-2 inhibitors were thought to confer greater cardiovascular safety concerns than COX-1 inhibitors. More recent data suggests that risk may accrue to all NSAIDs and has prompted regulatory authorities to mandate similar warnings regarding, cardiovascular, renal, and GI side effects on all NSAIDs [37]. Nevertheless, it is hypothesized that NSAIDS increase cardiovascular risk due to an increase in blood pressure resulting from $\mathrm{COX}-2$ inhibition in the kidneys and alteration of sodium and fluid retention. It is important to note that this increased risk is associated with long term dosing and likely is not an issue with acute use of NSAIDS as a class. Furthermore, naproxen may exhibit a lower cardiovascular risk relative to other NSAIDS due to its lower COX-2 selectivity, and has been shown not to affect blood pressure nor demonstrate any increased risk of cardiovascular events from short-term use [38]. Likewise, naproxen has not been associated with the same degree of interaction with aspirin as seen with ibuprofen and thus may be a preferred NSAID for patients on long term low-dose aspirin therapy [38-39,43]. While the incidence of adverse events is enough to mandate prescription status for certain doses and durations of NSAIDS, the OTC equivalent regimens have an improved safety profile such that physician supervision is only required in some instances. The lower dose and duration of these OTC regimens are associated with fewer GI side effects at a lower intensity and are most often reversible upon cessation [25]. As with all therapies, however, the risk of adverse events is not entirely eliminated. The OTC labeling advises consumers about measures that may attenuate adverse effects. Title 21 of the US Code of Federal Regulations defines the warnings that must appear on the label of NSAIDs. All OTC NSAIDs are required to advise consumers to ask their doctor if they have a history of stomach problems, cardiovascular disease, or kidney disease. In specific underlying conditions where there is an increased risk of bleeding, patients are advised to seek physician advice: advanced age, ulcers, bleeding problems, use of prescription NSAIDs, excessive alcohol consumption, or taking the product longer than directed. When a patient visits a physician for such advice, the physician will need to evaluate the risk and benefit of NSAID therapy in the context of these and other conditions. The risks of NSAIDs likely outweigh the benefit in patients with a history or increased risk of GI bleeding and in patients on concomitant oral anticoagulants [26], but should still be evaluated on a case-by-case basis against the potential benefits of NSAIDS, such as an opiate-sparing effect in a patient with respiratory depression.

\section{Bleeding Risk in the Post-Surgical Setting}

Invasive procedures damage tissues and consequently the blood vessels that perfuse those tissues. The extrinsic coagulation pathway is triggered during a surgery, involving a multitude of steps and specialized cells that should eventually result in wound healing. Inflammation is also triggered, leading to pain. Naproxen is effective in treating post-surgical inflammation and pain via COX inhibition. However, because COX inhibition carries a potential vascular risk, treatment with NSAIDs should be done at the lowest dose possible to minimize bleeding risk and its potential for interference with the wound healing process. 
Although healthcare providers may be concerned that NSAID use prior to surgery would lead to complications such as bleeding, they were not seen in studies that evaluated adverse effects of perioperative naproxen [3-9].

A Cochrane review found that for NSAID use in the post-surgical setting, most studies demonstrated significant efficacy findings but did not show a significantly increased incidence of adverse events compared to placebo [27]. Adverse events were generally of mild to moderate severity and rarely led to treatment discontinuation. Pooled safety data of OTC and prescription doses of naproxen when used for the treatment of postsurgical pain, not specific to a particular surgery, were evaluated in a Cochrane meta-analysis $(\mathrm{N}=$ 991). Compared to placebo, no individual study reported a significant difference in the rate of adverse events, including bleeding, for naproxen. Adverse event rates varied depending on the study and type of surgery, ranging from $9 \%$ to $37 \%$ for naproxen and $3 \%$ to $48 \%$ for placebo, but were not significantly different (risk ratio: $1.06,95 \%$ CI: 0.85 to $1.33, \mathrm{p}=$ $0.59)$. While some of the studies in this pooled analysis used prescription doses, the authors reported that they did not find a significant effect of the naproxen dose on the rate of adverse events including bleeding. [16] This conclusion was also reached in the other post-operative studies of naproxen that were reviewed [3-9]. A summary of the safety finding of these studies can be found in Table 1. One study specifically evaluated blood loss during orthopedic surgery for a combination of naproxen $(500 \mathrm{mg}$ ) and famotidine $(40 \mathrm{mg})$ daily for 7 days prior to surgery. Although a placebo was not used, blood loss in the control arm was not significantly different from naproxen intraoperatively $(641 \pm 287$ $\mathrm{mL}$ control vs. $719 \pm 314 \mathrm{~mL}$ ), postoperatively (464 $\pm 174 \mathrm{~mL}$ control vs. $440 \pm 195 \mathrm{~mL})$, or in total (1105 $\pm 373 \mathrm{~mL}$ control vs. $1159 \pm 399 \mathrm{~mL})$. Hemoglobin level was also not significantly different postoperatively $(11.0 \pm 0.7 \mathrm{~g} / \mathrm{dL}$ control vs. $11.1 \pm$ $0.6 \mathrm{~g} / \mathrm{dL})[28]$.

Although naproxen is contraindicated after cardiac procedures, there is nevertheless clinical data available in such procedures. A study evaluated blood loss during and after coronary artery bypass graft $(\mathrm{CABG})(\mathrm{N}=98)$. Naproxen was given at 500 mg twice over 24 hours immediately after surgery, followed by $250 \mathrm{mg}$ every 8 hours for 2 days afterwards. While naproxen use was associated with increased chest tube drainage during the initial four postoperative hours (1035 $\pm 88 \mathrm{~mL}$ naproxen vs. 732 $\pm 107 \mathrm{ml}$ placebo respectively, $\mathrm{P}=0.04$ ), there were no differences in the number of patients who required blood transfusion (48\% in both naproxen and placebo, $\mathrm{p}>0.99$ ) nor was there a significant difference in the amount of blood transfused (2.0 \pm 0.5 units in naproxen and $4.2 \pm 1.5$ units in placebo, $\mathrm{p}$ $=0.27)$. Neither the amount of packed red blood cells $(1.1 \pm 0.2$ units naproxen vs. $1.4 \pm 0.4$ units placebo, $\mathrm{p}=0.93)$ nor the platelets transfused $(0.1 \pm 0.1$ units naproxen vs. $0.5 \pm 0.5$ placebo, $p=0.08$ ) were significantly different [29]. Concurrent use of aspirin and naproxen would be expected to increase the risk of bleeding as a result of a pharmacodynamic interaction. While NSAIDS, including naproxen, have shown to interfere with the irreversible inhibition of platelet COX-1 by aspirin, the incidence of clinically significant bleeding with respect to this interaction with naproxen remains to be explored [38-39,44].

While naproxen has demonstrated consistent safety related to bleeding events in the post-operative setting, ibuprofen has had mixed safety findings. Ibuprofen use for post-tonsillectomy pain was associated with a significant increase in hemorrhage compared to placebo in more recent studies [30,31] but not older ones [32,33]. Caution should be warranted for ibuprofen use in the post-surgical setting until more data related to bleeding is available. Concurrent use of aspirin and ibuprofen can result in decreased antiplatelet effect of aspirin, increased risk of bleeding and cardiovascular events. It is recommended to use an NSAID that does not interfere with the antiplatelet effect of aspirin. If a patient taking prophylactic aspirin receives ibuprofen occasionally, it is recommended to administer aspirin at least 2 hours before or at least 8 hours after ibuprofen $[41,42]$.

\section{CONCLUSION}

Naproxen is an effective and safe medication recommended for first line use in many types of pain. In a diverse number of surgeries where patients experienced acute post-operative pain, naproxen has demonstrated a significant benefit over placebo. Importantly, the perioperative use of naproxen was not associated with an increase in adverse events including excessive or prolonged bleeding compared to placebo. Furthermore, the use of rescue medications, including opioids, was decreased in many studies. With an optimal NSAID dosing 
interval, efficacy demonstrated in a variety of surgeries, and safety comparable even to placebo with no evidence of a clinically or statistically significant increased bleeding or cardiovascular risk,

Table 1. Summary of Safety of Naproxen in Controlled Trials for Post-Operative Pain

\begin{tabular}{|c|c|c|c|c|}
\hline Citation & Subjects & $\begin{array}{l}\text { Interventional } \\
\text { Procedure }\end{array}$ & Naproxen Regimen & $\begin{array}{l}\text { Safety Results } \\
\text { Naproxen vs. Control }\end{array}$ \\
\hline $\begin{array}{l}\text { Cooper et al., } \\
\text { 2019[11] }\end{array}$ & 385 & $\begin{array}{l}\text { Impacted third } \\
\text { molar extraction }\end{array}$ & $\begin{array}{l}440 \mathrm{mg} \text { naproxen } \\
\text { sodium once }\end{array}$ & $\begin{array}{l}15.1 \% \text { treatment emergent AEs in naproxen } \\
\text { compared to } 29.1 \% \text { placebo }(\mathrm{p}=0.02) \text {, } \\
\text { compared to } 18.7 \% \text { ibuprofen }(\mathrm{p}=0.38)\end{array}$ \\
\hline $\begin{array}{l}\text { Derry et al., } \\
2009[16]\end{array}$ & 991 & $\begin{array}{l}\text { Pooled analysis of } \\
\text { multiple post-op } \\
\text { studies }\end{array}$ & Multiple & $\begin{array}{l}\text { Not significantly different than placebo } \\
\text { (risk ratio: } 1.06,95 \% \text { CI: } 0.85 \text { to } 1.33, p= \\
0.59 \text { ) for the pooled analysis, nor for any } \\
\text { individual study } \\
\text { Table } 1 \text { continues... }\end{array}$ \\
\hline $\begin{array}{l}\text { Kara et al., } \\
2010[3]\end{array}$ & 36 & $\begin{array}{l}\text { Impacted third } \\
\text { molar extraction }\end{array}$ & $\begin{array}{l}550 \mathrm{mg} \text { naproxen } \\
\text { sodium once }\end{array}$ & $\begin{array}{l}\text { Reports of nausea: } 1 \text { in naproxen, } 3 \text { in } \\
\text { control (not significantly different, not } \\
\text { determined to be related to study drug) }\end{array}$ \\
\hline $\begin{array}{l}\text { Mehrvarzfar et } \\
\text { al., 2012[4] }\end{array}$ & 100 & $\begin{array}{l}\text { Root canal with } \\
\text { irreversible } \\
\text { pulpitis }\end{array}$ & $\begin{array}{l}500 \mathrm{mg} \text { naproxen } \\
\text { once }\end{array}$ & $\begin{array}{l}\text { Not reported; no loss-to-follow-up or } \\
\text { discontinuation with naproxen. }\end{array}$ \\
\hline $\begin{array}{l}\text { Quiding et al., } \\
\text { 2013[5] }\end{array}$ & 103 & $\begin{array}{l}\text { Impacted third } \\
\text { molar extraction }\end{array}$ & $\begin{array}{l}500 \mathrm{mg} \text { naproxen } \\
\text { once }\end{array}$ & $\begin{array}{l}20 \% \text { for placebo and } 17 \% \text { for naproxen; all } \\
\text { mild or moderate intensity except one } \\
\text { placebo event }\end{array}$ \\
\hline $\begin{array}{l}\text { Young et al., } \\
\text { 2013[6] }\end{array}$ & 254 & $\begin{array}{l}\text { Impacted third } \\
\text { molar extraction }\end{array}$ & $\begin{array}{l}\text { naproxen } 250 \mathrm{mg} \text { or } \\
500 \mathrm{mg} \text { once }\end{array}$ & $\begin{array}{l}\text { No significant difference in AEs } \geq 5 \% \\
\text { between doses of naproxen, placebo not } \\
\text { significantly better than either dose of } \\
\text { naproxen. No serious AEs }\end{array}$ \\
\hline $\begin{array}{l}\text { Laurora et al., } \\
2016[7]\end{array}$ & 300 & $\begin{array}{l}\text { Impacted third } \\
\text { molar extraction } \\
\text { with mandibular } \\
\text { impaction }\end{array}$ & $\begin{array}{l}\text { naproxen sodium } 220 \\
\text { mg every } 8 \text { hours for } \\
24 \text { hours }\end{array}$ & $\begin{array}{l}28.3 \% \text { treatment emergent AEs in naproxen } \\
\text { vs. } 38.3 \% \text { placebo, all mild or moderate } \\
\text { intensity }\end{array}$ \\
\hline $\begin{array}{l}\text { Sammour et al., } \\
2011[8]\end{array}$ & 120 & Cesarean delivery & $\begin{array}{l}500 \text { mg naproxen } \\
\text { every } 8 \text { hours for } 48 \\
\text { hours }\end{array}$ & $\begin{array}{l}15 \% \text { in naproxen vs. } 30 \% \text { control } \\
\text { (tramadol; } \mathrm{p}=0.049 \text { ), } 0 \text { dropouts in } \\
\text { naproxen vs. } 15 \text { in control }\end{array}$ \\
\hline $\begin{array}{l}\text { Wang et al., } \\
2010[9]\end{array}$ & 100 & Bunionectomy & $\begin{array}{l}\text { naproxen sodium } 550 \\
\text { mg pre and post } \\
\text { every } 12 \text { hours for } 48 \\
\text { hours }\end{array}$ & $\begin{array}{l}83.3 \% \text { placebo vs. } 55.9 \% \text { naproxen, no } \\
\text { serious AEs }\end{array}$ \\
\hline
\end{tabular}

$\mathrm{AE}=$ adverse event $\mathrm{mg}=$ milligram.

FUNDING. The author disclosed receipt of the following financial support for the research, authorship, and/or publication of this article: funding was provided by Bayer HealthCare, Whippany, USA. The sponsor had no role in the writing of the article or in the decision to submit the article for publication.

AUTHORSHIP. The author meets the International Committee of Medical Journal Editors (ICMJE) criteria for authorship for this article, takes naproxen should be strongly considered as a treatment alternative when developing a pain management plan for a post-surgical patient. 


\section{REFERENCES}

1. Amaya F, Izumi Y, Matsuda M, Sasaki M. Tissue injury and related mediators of pain exacerbation. Curr Neuropharmacol. 2013 Dec;11(6):592-7.

2. Chou R, Gordon DB, de Leon-Casasola OA, et al. Management of Postoperative Pain: A Clinical Practice Guideline From the American Pain Society, the American Society of Regional Anesthesia and Pain Medicine, and the American Society of Anesthesiologists' Committee on Regional Anesthesia, Executive Committee, and Administrative Council. J Pain. 2016 Feb;17(2):131-57.

3. Kara IM, Polat S, Inci MF, Ince F, Gümüş C. Analgesic and anti-inflammatory effects of oxaprozin and naproxen sodium after removal of impacted lower third molars: a randomized, doubleblind, placebo-controlled crossover study. J Oral Maxillofac Surg. 2010 May;68(5):1018-24.

4. Mehrvarzfar P, Abbott PV, Saghiri MA, et al. Effects of three oral analgesics on postoperative pain following root canal preparation: a controlled clinical trial. Int Endod J. 2012 Jan;45(1):76-82.

5. Quiding H, Jonzon B, Svensson O, et al. TRPV1 antagonistic analgesic effect: a randomized study of AZD1386 in pain after third molar extraction. Pain. 2013 Jun;154(6):808-12.

6. Young CL, Strand V, Altman R, Daniels S. A phase 2 study of naproxen submicron particle capsules in patients with post-surgical dental pain. Adv Ther. 2013 Oct;30(10):885-96.

7. Laurora I, An R. Efficacy of single-dose, extendedrelease naproxen sodium $660 \mathrm{mg}$ in postsurgical dental pain: two double-blind, randomized, placebocontrolled trials. Curr Med Res Opin. 2016;32(2):331-42.

8. Sammour RN, Ohel G, Cohen M, Gonen R. Oral naproxen versus oral tramadol for analgesia after cesarean delivery. Int J Gynaecol Obstet. 2011 May;113(2):144-7.

9. Wang H, Gargano C, Lukac S, et al. An enhanced bunionectomy model as a potential tool for early decision-making in the development of new analgesics. Adv Ther. 2010 Dec;27(12):963-80.

10. Freeman WK, Gibbons RJ. Perioperative cardiovascular assessment of patients undergoing noncardiac surgery. Mayo Clin Proc. 2009;84(1):79-90.

11. Cooper SA, Desjardins P, Brain P, et al. Longer analgesic effect with naproxen sodium than ibuprofen in post-surgical dental pain: a randomized, double-blind, placebo-controlled, single-dose trial. Curr Med Res Opin. 2019 Dec;35(12):2149-58.
12. Kyeremateng K, Troullos E, Paredes-Diaz A. Safety of naproxen compared with placebo, ibuprofen and acetaminophen: a pooled analysis of eight multipledose, short-term, randomized controlled studies. Curr Med Res Opin. 2019 Oct;35(10):1671-6.

13. DeArmond B, Francisco CA, Lin JS, et al. Safety profile of over-the-counter naproxen sodium. Clin Ther. 1995 Aug;17(4):587-601; discussion 586.

14. Bangalore S, Kamalakkannan G, Parkar S, Messerli FH. Fixed-dose combinations improve medication compliance: a meta-analysis. Am J Med. 2007 Aug;120(8):713-9.

15. Grosser T, Ricciotti E, FitzGerald GA. The Cardiovascular Pharmacology of Nonsteroidal Anti-Inflammatory Drugs. Trends Pharmacol Sci. 2017;38(8):733-48.

16. Derry C, Derry S, Moore RA, McQuay HJ. Single dose oral naproxen and naproxen sodium for acute postoperative pain in adults. Cochrane Database Syst Rev. 2009 Jan 21;(1):CD004234.

17. Cattry E, Troullos E, Paredes-Diaz A. Efficacy and safety of naproxen sodium $440 \mathrm{mg}$ versus acetaminophen $600 \mathrm{mg} /$ codeine phosphate $60 \mathrm{mg}$ in the treatment of postoperative dental pain. Am J Dent. 2020 Apr;33(2):106-12.

18. Ogilvie-Harris DJ, Bauer M, Corey P. Prostaglandin inhibition and the rate of recovery after arthroscopic meniscectomy. A randomised double-blind prospective study. J Bone Joint Surg Br. 1985 Aug;67(4):567-71.

19. Code WE, Yip RW, Rooney ME, Browne PM, Hertz T. Preoperative naproxen sodium reduces postoperative pain following arthroscopic knee surgery. Can J Anaesth. 1994 Feb;41(2):98-101.

20. Drez D, Ritter M, Rosenberg TD. Pain relief after arthroscopy: naproxen sodium compared to propoxyphene napsylate with acetaminophen. South Med J. 1987 Apr;80(4):440-3.

21. Pedersen P, Nielsen KD, Jensen PE. The efficacy of Na-naproxen after diagnostic and therapeutic arthroscopy of the knee joint. Arthroscopy. 1993;9(2):170-3.

22. Binning A. Nimesulide in the treatment of postoperative pain: a double-blind, comparative study in patients undergoing arthroscopic knee surgery. Clin J Pain. 2007 Sep;23(7):565-70.

23. Angle PJ, Halpern SH, Leighton BL, et al. A randomized controlled trial examining the effect of naproxen on analgesia during the second day after cesarean delivery. Anesth Analg. 2002 Sep;95(3):741-5, table of contents.

24. Willoughby DA, Moore AR, Colville-Nash PR. COX-1, COX-2, and COX-3 and the future 
treatment of chronic inflammatory disease. Lancet. 2000 Feb 19;355(9204):646-8.

25. Rainsford KD, Adesioye J, Dawson S. Relative safety of NSAIDs and analgesics for nonprescription use or in equivalent doses. Inflammopharmacology. 2000 Dec 1;8(4):351-9.

26. Avouac B, Combe B, Darné B. [Prescription of NSAIDs in patients treatment with platelet inhibitors or anticoagulants]. Presse Med. 2003 Nov 22;32(37 Pt 2):S38-43.

27. Moore RA, Derry S, Aldington D, Wiffen PJ. Adverse events associated with single dose oral analgesics for acute postoperative pain in adults - an overview of Cochrane reviews. Cochrane Database Syst Rev. 2015 Oct 13;(10):CD011407.

28. Muñoz M, García-Vallejo JJ, Sempere JM, et al. Acute phase response in patients undergoing lumbar spinal surgery: modulation by perioperative treatment with naproxen and famotidine. Eur Spine J. 2004 Jul;13(4):367-73.

29. Kulik A, Ruel M, Bourke ME, et al. Postoperative naproxen after coronary artery bypass surgery: a double-blind randomized controlled trial. Eur $\mathbf{J}$ Cardiothorac Surg. 2004 Oct;26(4):694-700.

30. Mudd PA, Thottathil P, Giordano T, et al. Association Between Ibuprofen Use and Severity of Surgically Managed Posttonsillectomy Hemorrhage. JAMA Otolaryngol Head Neck Surg. 2017 01;143(7):712-7.

31. Swanson RT, Schubart JR, Carr MM. Association of ibuprofen use with post-tonsillectomy bleeding in older children. Am J Otolaryngol. 2018 Oct;39(5):618-22.

32. Krishna S, Hughes LF, Lin SY. Postoperative hemorrhage with nonsteroidal anti-inflammatory drug use after tonsillectomy: a meta-analysis. Arch Otolaryngol Head Neck Surg. 2003 Oct;129(10):1086-9.

33. Yaman H, Belada A, Yilmaz S. The effect of ibuprofen on postoperative hemorrhage following tonsillectomy in children. Eur Arch Otorhinolaryngol. 2011 Apr;268(4):615-7.

34. Product Information: ANAPROX(R) DS oral tablets, naproxen sodium oral tablets. Genentech USA, Inc. (per FDA), South San Francisco, CA, 2013.

35. Product Information: EC-Naprosyn delayed-release tablets, Naprosyn tablets, Anaprox/Anaprox DS tablets, Naprosyn suspension, naproxen delayedrelease tablets, naproxen tablets, naproxen sodium tablets, naproxen suspension. Roche Pharmaceuticals, Inc., Nutley, NJ, 2005.

36. Sevelius H, Runkel R, Segre E, Bloomfield SS. Bioavailability of naproxen sodium and its relationship to clinical analgesic effects. Br J Clin Pharmacol. 1980 Sep;10(3):259-63.

37. Katz JA. COX-2 inhibition: what we learned--a controversial update on safety data. Pain Med. 2013 Dec;14 Suppl 1:S29-34.

38. Angiolillo DJ, Weisman SM. Clinical Pharmacology and Cardiovascular Safety of Naproxen. Am J Cardiovasc Drugs. 2017;17(2):97107.

39. Gurbel PA, Bliden KP, Zhu J, Troullos E, Centofanti R, Jarvis S, Venkataraman P, Tantry US. Thromboxane inhibition during concurrent therapy with low-dose aspirin and over-the-counter naproxen sodium. J Thromb Thrombolysis. 2018 Jan;45(1):18-26.

40. Product Information: Motrin (R) oral tablets, ibuprofen oral tablets. Pharmacia \& Upjohn Company, Kalamazoo, MI, 2003.

41. Product Information: DUEXIS(R) oral tablets, ibuprofen famotidine oral tablets. Horizon Pharma USA, Inc. (per FDA), Lake Forest, IL, Jul, 2019.

42. US Food and Drug Administration: New Information for Healthcare Professionals Concomitant Use of Ibuprofen and Aspirin. US Food and Drug Administration, Rockville, MD, Sep 8, 2006. http://www.fda.gov/cder/drug/InfoSheets/HCP/ibu profen_aspirinHCP.htm.

43. Gengo FM, Rubin L, Robson M, Rainka M, Gengo MF, Mager DE, Bates V. Effects of ibuprofen on the magnitude and duration of aspirin's inhibition of platelet aggregation: clinical consequences in stroke prophylaxis. J Clin Pharmacol. 2008 Jan;48(1):11722. doi: 10.1177/0091270007310379.

44. Gladding PA, Webster MW, Farrell HB, Zeng IS, Park R, Ruijne N. The antiplatelet effect of six nonsteroidal anti-inflammatory drugs and their pharmacodynamic interaction with aspirin in healthy volunteers. Am J Cardiol. 2008 Apr 1;101(7):1060-3. doi: 10.1016/j.amjcard.2007. 11.054. Epub 2008 Feb 6. PMID:18359332. 